\title{
UJI TOKSISITAS AKUT MINUMAN PROBIOTIK SIRSAK GUNUNG (Annona montana Macf.) DENGAN METODE BSLT (Brine Shrimp Lethality Test)
}

\author{
Oleh \\ Ambar Fidyasari' ${ }^{1)}$, Sentot Joko Raharjo ${ }^{2)}$ \& Melani Setyowati ${ }^{3)}$ \\ 1,2,3 Akademi Analis Farmasi Dan Makanan Putra Indonesia Malang \\ Jl. Barito No 5 Malang-56123 \\ Email: ${ }^{\text {fidyafloss@gmail.com }}$
}

\begin{abstract}
Soursop fruit (Annona montana Macf.) is one of the plants can be used as as traditional medicine. This plant contains terpenoid and acetogenin which can cause toxicity. The fruit has a flavor that is tasteless so the innovation becomes probiotic drinks. This drink has been proven as an antioxidant, antibacterial, antihyperuricemia and antidiarrheal. The aim of this study was to know about acute toxicity of probiotic drink of soursop juice using brine shrimp lethality test method which will be indicated by $\mathrm{LC}_{50}$ value. This study used experimental methods conducted in the Laboratory of Farmakoknosi. There are several variations in concentration in this study, namely 10000 ppm, 20000 ppm, 30000 ppm, 40000 ppm, 50000 ppm, 60000 ppm, 70000 ppm, 80000 ppm and replication was done 3 times with total number of test animals used was 270 . The results showed that probiotic drink of soursop juice can provide acute toxic effects on test animals with $\mathrm{LC}_{50}$ value of $29717,23 \mathrm{ppm}$. $\mathrm{LC}_{5} 0$ values indicate that the mountain soursop probiotic drink is not potentially toxic because it has a value of $>1000 \mathrm{ppm}$.
\end{abstract}

Keywords: BSLT, Probiotic drinks, Soursop fruit \& Acute toxicity

\section{PENDAHULUAN}

Tanaman sirsak merupakan salah satu tanaman yang banyak digunakan masyarakat sebagai pengobatan alternatif. Tanaman sirsak terdiri dari 10 varietas, salah satunya sirsak gunung (Annona montana Macf.) (Dahana and Warisno, 2012). Pertumbuhan tanaman ini tergolong cepat dan selalu berbuah sepanjang musim.

Buah sirsak gunung (Annona montana Macf.) mengandung senyawa metabolit sekunder terpenoid dan termasuk dalam antioksidan kuat dengan nilai $\mathrm{IC}_{50} 61,93$ ppm (Wulandari, 2017). Buah sirsak gunung termasuk dalam famili annonaceae. Menurut Hanifah (2015) tanaman dengan famili tersebut memiliki senyawa metabolit sekunder acetogenin. Namun pemanfaatan buah sirsak gunung masih sangat rendah dikarenakan memiliki rasanya yang hambar, dan masam saat dikonsumsi sebagai buah segar. Sehingga diperlukan adanya upaya yang dapat meningkatkan penerimaan buah sirsak gunung di masyarakat, salah satunya dengan diolah menjadi minuman probiotik.

Minuman probiotik adalah minuman yang dibuat dengan cara fermentasi mengandung bakteri asam laktat (BAL). BAL merupakan salah satu jenis bakteri yang menguntungkan pada saluran pencernaan karena dapat meningkatkan keseimbangan flora usus (Tambunan, 2016). Kebanyakan bakteri asam laktat berasal dari genus Lactobacillus seperti Lactobacillus casei. Minuman probiotik dari hasil fermentasi sirsak gunung (Annonna montana Macf.) dapat digunakan sebagai antidiare dengan dosis yang efektif yaitu 0,30 ml/kgbb (Putri, 2017). Sumber lain juga menyebutkan bahwa minuman probiotik yang terbuat dari sari buah sirsak gunung (Annona montana Macf.) juga memiliki aktivitas penurunan berat badan mencit (Mus musculus L.) (Rohmah, 2018). Pada penelitian terdahulu telah dibuat menjadi sediaan berupa minuman probiotik. Namun belum diketahui toksisitasnya. 
Uji toksisitas adalah pemberian suatu senyawa terhadap hewan uji untuk menentukan suatu gejala dan tingkat kematian. Penelitian sebelumnya menyatakan bahwa minuman kombucha daun Tin (Ficus carica) berpotensi toksik karena memiliki nilai $\mathrm{LC}_{50}$ 139,99 ppm (Hasanah, 2019). Minuman probiotik sirsak gunung (Annona montana Macf.) sebelumnya sudah diteliti dan terbukti sebagai antioksidan oleh Wulandari (2017), antibakteri oleh Faizin (2019), antihiperurisemua oleh Hafiz (2018), dan antidiare (Putri, 2017). Salah satu metode yang digunakan untuk mengetahui aktivitas toksik dari suatu ekstrak atau senyawa bahan alam adalah Brine Shrimp Lethality Test (BSLT) (Setyowati and Cahyanto, 2016).

Brine Shrimp Lethality Test (BSLT) merupakan suatu metode yang sering digunakan sebagai skrining awal terhadap senyawa aktif yang terkandung dalam tumbuhan, karena relatif murah, cepat dan hasilnya (Cahyadi, 2009). Menurut Setyowati and Cahyanto (2016) metode BSLT juga memiliki tingkat kepercayaan hingga 95\%.. Hewan uji yang digunakan yaitu Artemia salina Leach yang berumur 48 jam karena memiliki daya resistensi yang rendah terhadap lingkungan (Refli, 2012). Selain itu hasil penelitian toksisitas menggunakan metode BSLT juga bisa digunakan sebagai skrining awal senyawa sitotoksik atau senyawa yang berpotensi sebagai antikanker dengan cara menghitung nilai LC50. Ekstrak dikatakan toksik berdasarkan metode BSLT jika harga $\mathrm{LC}_{50} \leq 1000 \mu \mathrm{g} / \mathrm{ml}$ sedangkan untuk senyawa murni jika LC L0 $_{53} \leq 3 \mathrm{~g} / \mathrm{ml}$ (Hasanah, 2019).

Melalui latar belakang diatas maka perlu dilakukan uji toksisitas terhadap minuman probiotik sirsak gunung (Annona montana Macf.) dengan metode Brine Shrimp Lethality Test (BSLT) diharapkan dapat memberikan hasil yang nantinya dapat dijadikan bahan informasi tentang potensi toksik dari minuman probiotik (Annona montana Macf.).

\section{METODE PENELITIAN}

Uji toksisitas akut minuman probiotik sirsak gunung (Annona montana Macf.) menggunakan metode penelitian eksprimental. Alat dan Bahan

Alat yang digunakan adalah timbangan analitik (Ohaus), kain saring, blender (Miyako), peralatan gelas (Pyrex), panci, termometer, incubator (Memmert IN30), kompor, lampu neon (Philips), lakban, alumunium foil, pipet volume, jarum ose, kertas coklat, kapas, pepet ukur, beaker glass, autoclave (American Tipe 75X) dan aerator.

Bahan yang digunakan adalah buah sirsak gunung (Annona montana Macf.) diambil dari kebun Jl. Barito No 6 Malang, starter Lactobacillus casei yang didapatkan dari produk komersial, aquadest, larva udang Artemia salina Leach didapatkan dari Fakultas Perikanan Universitas Muhammadiyah Malang dan air laut asli dengan $\mathrm{pH}$ 8-9.

\section{Tahap Penelitian}

Pada penelitian ini dilakukan proses pembuatan sari buah sirsak gunung dengan perbandingan 1:2 terhadap air. Kemudian dilakukan proses pembuatan minuman probiotik dengan penambahan strain Lactobacillus casei dari produk komersial dan diinkubasi 24 jam.

Langkah selanjutnya setelah didapatkan minuman probiotik dilakukan pengujian berupa organoleptis, nilai $\mathrm{pH}$. Pengujian organoleptis menggunakan panca indera manusia, antara lain yaitu aroma (penciuman), rasa (pengecap), warna (penglihatan), dan tekstur (peraba) hasil disesuaikan dengan SNI 7552-2009. Pengujian nilai $\mathrm{pH}$ menggunakan $\mathrm{pH}$ meter disesuaikan dengan standart $\mathrm{pH}$ minuman probiotik 4,5 (Kuswinarto, 2017)

Pada penelitian sebelumnya, uji toksisitas akut dilakukan dengan menggunakan metode BSLT. Langkah pertama yaitu penetasan larva Artemia salina Leach menggunakan air laut yang diberi lampu neon dan aerator. Penetasan dilakukan selama 48 jam. Terdapat 8 konsentrasi larutan uji dan 1 kontrol negatif yang digunakan. Pengujian toksisitas akut 
menggunakan 10 ekor larva tiap tabung dengan replikasi sebanyak tiga kali. Observasi larva dilakukan selama 24 jam. Persentase kematian diperoleh dengan cara jumlah kematian larva dibagi total larva tiap konsentrasi (Mutammimah and Santoso, 2019). Hasil dari analisa probit dengan menggunakan microsoft excel.

\section{HASIL DAN PEMBAHASAN}

Penelitian dilaksanakan pada bulan Maret 2020 di Laboratorium Farmakognosi Putra Indonesia Malang.

Tabel 1. Uji Organoleptis Minuman Probiotik Sirsak Gunung

\begin{tabular}{|c|c|}
\hline Organoleptis & Hasil \\
\hline Fisik & Cair \\
\hline Warna & Kuning Pucat \\
\hline Bau & $\begin{array}{c}\text { Khas Sirsak } \\
\text { Gunung }\end{array}$ \\
\hline Rasa & Sedikit Asam \\
\hline
\end{tabular}

Tabel 2. Uji pH Minuman Probiotik Sirsak Gunung

\begin{tabular}{|c|c|}
\hline $\begin{array}{c}\text { pH sebelum } \\
\text { diinkubasi }\end{array}$ & $\begin{array}{c}\text { pH setelah } \\
\text { diinkubasi }\end{array}$ \\
\hline $\mathbf{4 , 7 8}$ & 4,503 \\
\hline
\end{tabular}

Tabel 3. Hasil Pengamatan Angka Probit

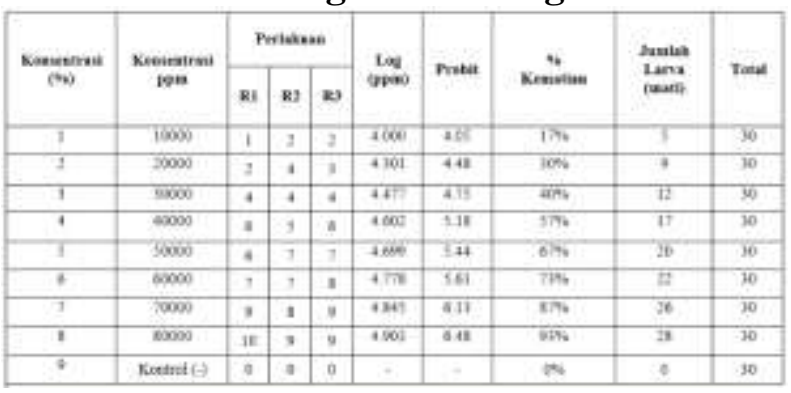

Gambar 1. Regresi Linier Log (ppm) dan

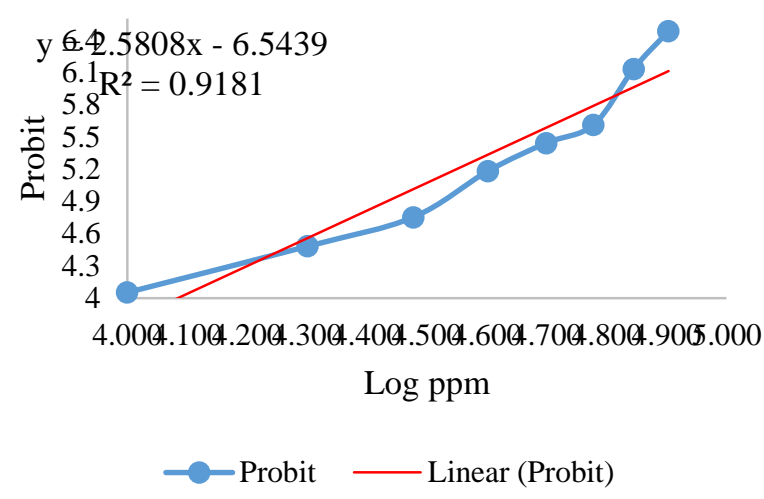

Probit

Nilai LC50

Nilai LC $_{50}$ didapatkan menggunakan persamaan regresi linier. $\mathrm{LC}_{50}$ minuman probiotik sirsak gunung (Annona montana Macf.) sebesar 29717.2306 ppm atau $2.9712 \%$.

\section{Pembahasan}

Hasil minuman probiotik sirsak gunung yang dihasilkan rasanya sedikit asam, aromanya khas buah sirsak gunung, dan berwarna kuning pucat. Hasil yang didapat minuman probiotik sirsak gunung yaitu memiliki ciri fisik cair, hal ini sesuai dengan Standar Nasional Indonesia 7552-2009 yang menyatakan bahwa minuman fermentasi memiliki ciri fisik cair.

Nilai $\mathrm{pH}$ yang didapatkan sebelum dan sesudah inkubasi selama 24 jam yaitu 4,78 dan 4,505. Pengecekan nilai $\mathrm{pH}$ bertujuan untuk mengetahui adanya proses fermentasi pada minuman sirsak gunung dengan adanya penurunan nilai $\mathrm{pH}$. Hal tersebut disebabkan karena adanya aktivitas bakteri asam laktat (BAL) yang berkerja menfermentasi gula (sukrosa, fruktosa, glukosa dan laktosa) menjadi sebagian asam laktat dan sejumlah kecil asam lainnya. Fermentasi yang melibatkan BAL memiliki ciri terakumulasinya asam-asam organik yang diiringi terjadinya penurunan nilai $\mathrm{pH}$ yang berhubungan dengan total asam yang dihasilkan selama proses fermentasi (Boro, 2017). Selain itu, menurut (Primurdia and Kusnadi, 2014) penurunan nilai 
$\mathrm{pH}$ disebabkan oleh peningkatan jumlah asam asam organik yang merupakan hasil metabolisme dari bakteri asam laktat yang ada pada minuman probiotik. Asam laktat yang dihasilkan sebagai produk utama akan terdisosiasi menghasilkan $\mathrm{H}+$ dan $\mathrm{CH}_{3} \mathrm{CHOHCOO}-$, sehingga semakin tingginya asam laktat memungkinkan tingginya ion $\mathrm{H}^{+}$ yang terbebaskan dalam medium sehingga menurunkan nilai $\mathrm{pH}$ minuman probiotik. Didapatkan $\mathrm{pH}$ minuman probiotik sirsak gunung sebesar 4,508 yang sesuai dengan standar $\mathrm{pH}$ minuman probiotik sebesar 4,5 (Kuswinarto, 2017).

Menurut penelitian yang dilakukan oleh Wulandari (2014) sirsak gunung mengandung senyawa metabolit sekunder terpenoid. Senyawa tersebut diduga dapat menyebabkan toksisitas akut. Uji toksisitas akut minuman probiotik sirsak gunung menggunakan hewan uji Artemia salina yang berumur 2 hari. Hal ini dikarenakan larva memiliki daya resistensi yang rendah terhadap lingkungan serta sudah memiliki anggota tubuh yang lengkap (Refli, 2012). Dilakukan pengecekan secara mikroskopis yang berfungsi untuk memastikan jenis larva Artemia salina yang digunakan sesuai dengan literatur.

Uji trial and error dilakukan sebanyak 3 kali dengan berbagai konsentrasi, hal ini dikarenakan untuk mendapatkan konsentrasi yang dapat membunuh lebih dari $50 \%$ larva udang. Pengulangan sebanyak 3 kali dengan total hewan uji sebanyak (30 ekor), pengulangan dilakukan untuk mendapatkan data yang akurat, dikarenakan untuk menghindari kemungkinan adanya kesalahan dan tidak ada data lain yang digunakan apabila hanya dilakukan satu kali.

Didapatkan konsentrasi yang digunakan setelah dilakukan trial and error yaitu $1 \%, 2 \%$, $3 \%, 4 \%, 5 \%, 6 \%, 7 \%$ dan $8 \%$ atau jika dirubah dalam bentuk ppm yaitu 10000 ppm, 20000 ppm, 30000 ppm, 40000 ppm, 50000 ppm, 60000 ppm, 70000 ppm dan 80000 ppm. Selain itu dibuat kontrol negatif yang hanya berisi air laut saja, hal ini bertujuan untuk mengetahui apakah larva Artemia salina mati karena faktor minuman probiotik sirsak gunung ataupun karena zat lain (air laut) yang digunakan. Pengujian dilakukan secara triplo atau tiga kali replikasi dengan total larva Artemia salina sebanyak 270 ekor. Pengujian dilakukan menggunakan tabung reaksi yang berisi larva udang masing-masing sebanyak 10 ekor, air laut dan larutan uji minuman probiotik dengan berbagai konsentrasi. Uji toksisitas dilakukan selama 24 jam. Hasil uji toksisitas akut dilihat adanya kematian larva yang ditandai dengan tidak adanya pergerakan selama 10 detik observasi. Didapatkan nilai $\mathrm{LC}_{50}$ minuman probiotik sirsak gunung sebesar 29.717,23 ppm. Berdasarkan tabel konsentrasi larutan uji semakin besar kematian larva dan nilai probitnya.

Didapatkan nilai LC $_{50}$ sebesar 29.716,17 ppm yang artinya pada konsentrasi $29.716,17$ ppm minuman probiotik sirsak gunung dapat membunuh larva udang Artemia salina Leach. Suatu senyawa dikatakan memiliki kategori tidak toksik jika memiliki harga $\mathrm{LC}_{50}$ lebih dari 1.000 ppm (Cahyadi, 2009). Hal tersebut dikarenakan mortalitas larva Artemia salina Leach yang rendah yaitu pada konsentrasi < $1000 \mu \mathrm{g} / \mathrm{mL}$ mortalitas tidak mencapai sebesar $50 \%$ dari jumlah larva yang diujikan. Selain itu, diduga pada minuman probiotik sirsak gunung tidak mengandung senyawa metabolit sekunder atau senyawa tersebut tersebut tidak terdeteksi pada konsentrasi yang diinginkan sehingga bersifat tidak toksik (Hendri and Puspitasari, 2018). Fermentasi dapat mempengaruhi total fenolik dan aktivitas antioksidan dengan tingkat pengaruh tergantung pada spesies mikroorganisme yang digunakan. Penelitian oleh Wijayanti et al., (2017) menyatakan bahwa fermentasi buah tin menggunakan BAL dapat menurunkan kadar flavonoid. Sejalan dengan Penelitian oleh Fidyasari et al., (2017) yang menyatakan bahwa ekstrak sirsak gunung memiliki aktivitas antioksidan kuat dengan nilai $\mathrm{IC}_{50}$ sebesar $61,93 \mathrm{ppm}$. Namun, setelah dilakukan proses fermentasi dengan menggunakan jenis BAL yang berbeda 
mengalami penurunan kadar fenolik sehingga terjadi peningkatan nilai IC $\mathrm{IC}_{50}$ sebesar 5.327,315 ppm. Peningkatan nilai tersebut dikarenakan senyawa fenolik tidak tahan panas pada saat proses pasteurisasi. Menurut Anggraeni et al., (2015) senyawa fenol merupakan senyawa senyawa yang sangat mudah teroksidasi dan dipengaruhi oleh cahaya dan suhu. Semakin lama proses pemanasan dan semakin tinggi suhu yang digunakan pada saat pengolahan, maka senyawa fenol yang berperan sebagai antioksidan semakin banyak yang hilang.

Hal serupa juga terjadi pada fermentasi sirsak gunung yang mengandung karotenoid yaitu pigmen yang memberikan warna kuning, jingga hingga merah. Karotenoid berfungsi sebagai antioksidan, antikanker, dan membantu memelihara kesehatan mata. Wahyuni and Widjanarko (2015) dalam penelitiannya menyebutkan bahwa pada $\mathrm{pH} 3$ dan 5 absorbansi karotenoid cenderung turun yang menandakan bahwa warna pada karotenoid memudar. Absorbansi karotenoid labu kuning yang diatur dengan $\mathrm{pH} \mathrm{7,10} \mathrm{dan} 13$ tampak tidak memberikan pengaruh signifikan terhadap degradasi pigmen karotenoid labu kuning. Artinya pigmen karotenoid labu kuning cukup stabil terhadap larutan $\mathrm{pH}$ yang bersifat netral dan basa. Karotenoid stabil pada $\mathrm{pH}$ netral, alkali namun tidak stabil pada kondisi asam, adanya udara atau oksigen, cahaya dan panas. Karotenoid tidak stabil karena mudah teroksidasi oleh adanya oksigen dan peroksida. Selain itu, dapat mengalami isomerisasi bila terkena panas, cahaya dan asam. Kebanyakan karotenoid stabil terhadap basa namun beberapa karotenoid seperti astaksantin dan fukosantin peka terhadap alkali. Hal ini juga yang dapat menyebabkan nilai $\mathrm{IC}_{50}$ maupun fenolik pada fermentasi sirsak gunung meningkat dibandingkan dengan ekstrak buahnya.

Hasil tidak toksik pada minuman probiotik sirsak gunung dapat diartikan bahwa tidak adanya potensi toksik sehingga dapat dilakukan penelitian lebih lanjut tentang khasiat atau manfaatnya. Sebelumnya telah dilakukan penelitian tentang manfaat minuman probiotik sirsak gunung, diantaranya penelitian yang dilakukan oleh Putri (2017) yang menyebutkan bahwa minuman probiotik sirsak gunung dapat digunakan sebagai antidiare dengan dosis yang paling efektif yaitu $0,30 \mathrm{ml} / \mathrm{kgbb}$. Hafiz (2018) juga menyatakan bahwa minuman probiotik sirsak gunung memiliki aktivitas sebagai antihiperurisemia. Minuman probiotik sirsak gunung memiliki aktivitas antibakteri terhadap Salmononella sp walaupun tergolong kategori lemah (Faizin, 2019). Selain itu penelitian yang dilakukan oleh Rohmah (2018) menyatakan minuman probiotik sirsak gunung dapat menurunkan berat bedan mencit

\section{PENUTUP}

\section{Kesimpulan}

Minuman Probiotik sirsak gunung tidak bersifat toksik dengan nilai $\mathrm{LC}_{50}$ sebesar $29717.2306 \mathrm{ppm}$ atau $2.9712 \%$.

\section{DAFTAR PUSTAKA}

[1] Anggraeni et al., 2015. Aktivitas Antioksidan Ekstrak Berbagai Hasil Olah Ubi Jalar. Jurnal Rekapangan. 1, 1-7.

[2] Boro, I.L., 2017. Mutu Fisik Dan Mikrobiologi Minuman Probiotik Sari Buah Sirsak Gunung (Annona Montana Macf) Dengan Penambahan Lactobacillus casei. Karya Tulis Ilmiah tidak diterbitkan. Malang: Akademi Farmasi Putera Indonesia Malang.

[3] Cahyadi, R., 2009. Uji Toksisitas Akut Ekstrak Etanol Buah Pare (Momordica charantia 1.) Terhadap Larva Artemia salina Leach Dengan Metode Brine Shrimp Lethality Test (BSLT). Fakultas Kedokteran. Universitas Diponegoro. Semarang.

[4] Dahana, K., Warisno, 2012. Daun Sirsak Langkah Alternatif Menggempur Penyakit. Jakarta: PT. Gramedia Pustaka Utama.

[5] Faizin, M., 2019. Uji Aktivitas Antibakteri Dari Minuman Probiotik Sirsak Gunung (Annona montana Macf.) Dalam Menghambat Pertumbuhan Bakteri Salmonella sp. Karya Tulis Ilmiah. Akademi Farmasi Putra Indonesia Malang. 
[6] Fidyasari, A., Sari, M.I., Wahyu, D.E., 2017. Pengaruh Minuman Probiotik Sirsak Gunung (Annona Montana Macf.) Terhadap Kadar Malondialdehid (MDA) dan Superoksida Dismutase(SOD). Research Report. 463-468.

[7] Hafiz, M., 2018. Aktivitas Sari Buah Sirsak Gunung Dan Minuman Probiotik Buah Sirsak Gunung (Annona montana) Terhadap Penurunan Kadar Asam Urat Pada Mencit (Mus musculus L.). Karya Tulis Ilmiah. Akademi Farmasi Putra Indonesia Malang.

[8] Hanifah, N.Z., 2015. Uji Toksisitas Akut Ekstrak Metabol Daun Annona muricata L Terhadap Larva Artemia salina Leach Dengan Metode Brine Shrimp Lethality Test (BSLT). Skripsi. Fak. Kedokteran dan Ilmu Kesehatan. UIN Syarif Hidayatullah. Jakarta.

[9] Hasanah, U., 2019. Toksisitas Akut Kombucha Daun Tin (Ficus carica) Berdasarkan Nilai LC50 Terhadap Larva Udang (Artemia salina). Karya Tulis Ilmiah. Akademi Farmasi Putra Indonesia Malang.

[10]Hendri, M., Puspitasari, E., 2018. Uji Toksisitas dengan Menggunakan Metode Brine Shrimp Lethality Test (BSLT) pada Ekstrak Mangrove (Avicennia Marina, Rhizophora Mucronata, Sonneratia Alba dan Xylocarpus Granatum) yang Berasal dari Banyuasin, Sumatera Selatan. Jurnal Biologi Tropis. 18, 91-103.

[11] Kuswinarto, R.R., 2017. Pengaruh konsentrasi starter dan lama fermentasi terhadap karakteristik Fruitghurt sari kulit Pisang Ambon (Musa paradisiaca L.). Skripsi. Fak Sains dan teknologi. Universitas Islam Negeri Maulana Malik Ibrahim. Malang.

[12] Mutammimah, N., Santoso, B.S., 2019. Uji Toksisitas Akut Infusa Buah Mengkudu (Morinda citrifolia L.) Pada Artemia salina Menggunakan Metode Brine Shrimp Lethality Test (BSLT). J. Farm. Medic Pharmacy Med. J. PMJ 2 (2), 75-79.
[13] setyowaPrimurdia, E.G., Kusnadi, J., 2014. Aktivitas Antioksidan Minuman Probiotik Sari Kurma (Phoenix dactilyfera L.) dengan Isolat L. plantarum dan L. casei. J. Pangan Dan Agroindustri (2), 98-109.

[14]Putri, D.A., 2017. Keefektifan Antidiare Minuman Probiotik Dari Fermentasi Buah Sirsak Gunung (Annona montana Macf.) Pada Mencit (Mus musculus) Yang Terinfeksi Bakteri Escherichia coli. Karya Tulis Ilmiah. Akademi Farmasi Putra Indonesia Malang.

[15]Refli, R., 2012. Potensi Ekstrak Daun Tin (Ficus carica L.) Sebagai Antioksidan Dan Aktivitas Hambatnya Terhadap Ploriferasi Sel Kanker HeLa. Skripsi. Fak Matematika dan IPA. IPB. Bogor.

[16]Rohmah, U., 2018. Aktivitas Sari Buah Sirsak Gunung dan Minuman Probiotik Buah Sirsak Gunung (Annona montana Macf.) Terhadap Penurunan Berat Mencit (Mus musculus L.). Karya Tulis Ilmiah. Akademi Farmasi Putra Indonesia Malang.

[17] Setyowati, W.A.E., Cahyanto, M.A.S., 2016. Kandungan Kimia dan Uji Aktivitas Toksik Menggunakan Metode BSLT (Brine Shrimp Lethality Test) dari Ekstrak Daun Kersen (Muntingia calabura). J. Kimia dan Pendidikan Kimia. (1), 41-47.

[18] Tambunan, A.R., 2016. Karakteristik Probiotik Berbagai Jenis Bakteri Asam Laktat (BAL) Pada Minuman Fermentasi Laktat Sari Buah Nanas. Skripsi. Fak Pertanian. Universitas Lampung.

[19] Wahyuni, D.T., Widjanarko, S.B., 2015. Pengaruh Jenis Pelarut Dan Lama Ekstraksi Terhadap Ekstrak Karotenoid Labu Kuning Dengan Metode Gelombang Ultrasonik. J. Pangan Dan Agroindustri, 2 3, 397-399.

[20] Wijayanti, E.D., Setiawan, N.C.E., Cristi, J.P., 2017. Effect of Lactic Acid Fermentation on Total Phenolic Content and Antioxidant Activity of Fig Fruit Juice (Ficus carica). Journal Biological Researches. 2, 284-287. 
[21]Wulandari, F., 2014. Uji Toksisitas Akut Ekstrak Metanol Daun Mahkota Dewa (Phaleria macrocarpa terhadap Larva Artemia salina Leach Dengan Metode Brine Shrimp Lethality Test (BSLT). Skripsi. Fakultas Kedokteran dan Ilmu Kesehatan. Jakarta: Universitas Islam Negeri.

[22] Wulandari, S., 2017. Senyawa Metabolit Sekunder Dan Aktivitas Antioksidan Pada Ekstrak Buah Sirsak Gunung (Annona montana). Karya Tulis Ilmiah tidak diterbitkan. Malang: Akademi Farmasi Putera Indonesia Malang. 
HALAMAN INI SENGAJA DIKOSONGKAN 